\title{
Evolution of medical architecture
}

\author{
Nadezhda Tesler $^{1^{*}}$ \\ ${ }^{1}$ Moscow State University of Civil Engineering, Yaroslavskoe shosse, 26, Moscow, 129337, Russia
}

\begin{abstract}
This article deals with the history of medical architecture development in Russia and abroad. Numerous examples of buildings of healthcare facilities, from ancient times to the present day, are given. Buildings of hospitals and clinics were erected in the architectural traditions then prevailing. Features of healthcare facilities, which determine their architectural concept, are: type and purpose of the healthcare facility, scope and structure of medical services, location in the urban environment, architectural environment, etc. When designing the construction and reconstruction of hospitals and outpatient clinics, parameters of wards, doctor's offices, procedure and administrative premises shall be taken into account. Special attention shall be paid to requirements to surgical theaters, intensive care units and other facilities with sophisticated equipment and numerous utilities.
\end{abstract}

\section{Introduction}

Since ancient times, health care has been associated with the construction and use of specialized medical buildings and structures. To take right architectural and design solutions for modern medical buildings, the history of development of medical architecture in various countries must be studied.

\section{Development of medical architecture since ancient times}

The Ancient Egypt laid the foundation of architecture as art of design and construction. Residential and public buildings were constructed mainly of air-died brick, so they almost did not survive, and stone was used only for tombs and temples. Interestingly, the first known ancient Egyptian architect, creator of the first pyramid of Imhotep (27th century $\mathrm{BC}$ ) is also considered the founder of ancient medicine.

Archaeological study of the city of Mohenjo Daro (about 27th-15th centuries BC, Pakistan) suggests that there were although not medical, but sanitary facilities: wells, baths, drains, public toilets, and sewage systems.

It is assumed that already in Ancient Mesopotamia (3rd millennium BC) there were clinics at temples, where nobles were treated. Medical hospitals established for permanent care were also known in India about $100 \mathrm{BC}$ [1]. At the beginning of the new era, in China, there was a state-sponsored chain of hospitals. Some consider Mihintale Hospital (Sri

\footnotetext{
* Corresponding author: nadya.tesler@gmail.com
} 
Lanka), founded in the 3rd century BC during the spread of Buddhism in Ceylon, to be the world's oldest [2].

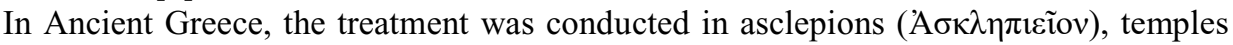
of Asclepius, god of medicine, which were both religious and therapeutic facilities of outpatient nature. The ruins of asclepions preserved on the Kos island, in Pergamos, Cnidus, Epidaurus, while in the latter (6th century BC), surgical instruments, marble, gold and silver images of cured organs and even a marble slab with case records of 70 patients were found. The total of up to 300 asclepions were mentioned. The majestic Asclepion of Pergamum was built in the 6th century BC, first as a temple, and later was rebuilt several times [3]. The asclepion of Kos, where Hippocrates was born and studied medicine, consisted of three levels. The first floor housed the Museum of Anatomy and an educational institution. On the second floor, there were medicinal baths and halls, on the third - the Temple of Asclepius itself. Along the walls of the temple, a portico (abaton

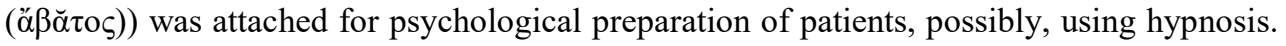
An asclepion often had baths, a library, a stadium and a theater. Thus, there were no sharp boundaries between a secular hospital and a temple [4].

In Ancient Rome, the cult of Asclepius was adopted under the name of Aesculapius. A temple on the Tiber Island in Rome (291 BC) was dedicated to him. Aqueducts, baths, and swimming pools were widespread. Buildings for care of sick and wounded soldiers, gladiators and slaves (valetudinariums) were built in the 1st century BC, but there were no civil hospitals in Rome yet. The traditions of ancient medical architecture were perceived by the emerging Christian civilization. After the Council of Nicaea (325 AD), public hospitals were built in each city, where there was a cathedral. They were mainly used for the poorest population. The first hospital in the Byzantine Empire was built by Archbishop Leonty in 344-358 in Antioch (modern Antakya, Turkey). With the advent of the first monasteries in the 4th century, xenodochia (monastery shelters for crippled and sick travelers) began to emerge [4].

Ruins of a Byzantine hospital, which was built in the Greek colony of Side (modern Turkey) in the 6th century AD, give an idea about the structure of inpatient facilities. The hospital was a two-story building, with the dimensions of $27 \times 16.5 \mathrm{~m}$, and contained five vaulted blocks separated by arches, for three wards each. The walls are built of natural stone and of material of early Roman buildings. Subsequently, hospitals in the Seljuk Empire were followed this example.

However, in the early Middle Ages, after the fall of the ancient states, social function of hospitals dominated over the medical due to the extremely low level of medical knowledge. Hospitals were rather shelters and hospices than full-fledged healthcare facilities. However, many hospitals emerged in Western Europe in the 6th-8th centuries. Later, in the 12th and 13th centuries, the knowledge of classical and Eastern healers began to penetrate Europe.

In the Muslim world, hospitals appeared since the 7th century. Many hospitals were established by the state (Caliphs) and served broad population. In particular, in Baghdad by 1160, there were more than 60 hospitals [5]. Medical schools were established at hospitals. Furthermore, the establishment of hospitals was arranged by religious leaders and the army.

By the Middle Ages, the share of knowledge based on practical observations began to increase in medical science. Training of doctors and accumulation of practical medical observations was inextricably linked with the health care, and that gave the impetus for formation of first multifunctional healthcare facilities. One of the earliest examples of such a structure is Schola Medica Salernitana, founded in the 9th century under the auspices of the monastic hospital in Italy. Until the 13th century, this institution was considered to be a leading center of medical education and science in Europe and was issuing licenses to practice. 
In 1118-1124, in Constantinople, John II Komnenos built a hospital at the Monastery of the Pantocrator. The building had heating, natural and artificial lighting, facilities for bathing and toilets. The building survived, transformed nowadays into the Zeyrek Camii mosque. In the Christian quarter of the Jerusalem Citadel, recently, a gallery of 6-meter arches of the 12th century was found, which was part of a large ancient hospital founded by the Hospitallers. It accommodated up to 2000 patients - pilgrims of various religious beliefs. Arches separated wards and procedure halls. The superstructure of the building was destroyed by the earthquake of 1457 [6].

In other countries, the architecture of hospitals was also influenced by local and church traditions. For instance, in Scotland in 1164, King Malcolm IV founded Sutra Isle hospital at the monastery of the Holy Trinity, the building of which has clear signs of Romanesque style. In Renaissance, in Europe, pharmacy shops, labs, pharmacopoeia, and botanical gardens emerged. In the later Middle Ages, the integration phase of the health-care process, medical science and education came up in Western Europe. The first university medical center was formed in Heidelberg, Germany, and is currently operating. In the 16th century, it was established by the Faculty of Medicine, and at the end of the 16th century a hospital was opened at it, a pharmacological laboratory was established. At the beginning of the 19th century, an outpatient clinic was opened at the Faculty of Medicine of the Heidelberg University. Thus, the University Medical Center in Heidelberg is one of the earliest examples of a multifunctional healthcare facility, combining healthcare, scientific, educational and pharmaceutical units. Built in 1906 Samariterhaus is currently the Clinic for Radiation Therapy at the Heidelberg University.

In modern times, well equipped hospitals emerge in all major cities abroad. The state, in one way or another, supports medical care, however, social stratification persists; private for-profit hospitals render more expensive and high-tech services. To reduce social tensions, various health insurance system are introduced to provide medical care, where necessary, at the expense of the insurance proceeds. At the same time, the impact of religious organizations is decreasing, the healthcare becomes more secular.

With the growing volume of inpatient medical care, the conditions of stay in hospitals are improved, buildings are equipped with sophisticated technical engineering systems, electronics, and communications. Wards for 1-2 beds become common, periods of stay in hospitals are reduced. Outpatient treatment is also improved.

The arrangement of multifunctional healthcare facilities has two trends: studio buildings and high-rise buildings - the latter trend manifests itself in the United States. The latest trend is to create medical clusters that bring together multi-disciplinary hospitals, ambulatory clinic, outpatient clinics, rehabilitation centers, and medical universities.

Modern medical buildings may have both strict functional and ultra-modern form.

\section{Medical architecture in Russia}

The Kievo-Pecherska Lavra (11-12th centuries), where Greek doctors worked, may be considered the first known health-care facility in Russia. It is also known that in the 14th century there were hospitals in Novgorod, the Kirillo-Belozersky monastery, in Preslavl and other cities. However, the Mongol invasion put an end to the development of architecture both of civic buildings in general and healthcare facilities in particular, for long. At the end of the 16th century in Kiev, Moscow, Pskov and other cities, public hospitals and almshouses emerged. It is known that a temporary military hospital was established in Smolensk in 1656 to assist those wounded in battles with Polish and Swedish troops. In addition, in the mid-17th century, a secular almshouse hospital belonging to enlightened boyar F. M. Rtishchev was set up. 
However, until the beginning of the 18th century, for the majority of the population of Russia, traditional medicine based on herbalism and other natural remedies remained the only mean of maintaining their health. There were no large civil hospitals in Russia.

Under Peter the Great, military medicine emerged in Russia, the first sanatorium Martial Waters was also founded near mineral springs (1719, recreated in 1964). During the reign of Catherine the Great, civilian hospitals were established.

The Pavlovskaya hospital was founded in 1763, to celebrate the recovery of the heir to the throne, the future Emperor Paul I, and consisted of wooden buildings along Pavlovskaya Street. In 1803, M.F. Kazakov erected a stone building with a dome, a portico and projections; two wings were added in 1830 by D.Gilardi. Now it houses the 4th Moscow City Hospital.

The "old" St. Catherine's Hospital was opened in 1776 at the place of the antiplague quarantine station, at 3rd Meshchanskaya Street (modern Shchepkina St.) and occupied wooden buildings. Stone buildings were erected in 1877-1881 by A.A. Meingard, in 1899 by V.P. Desyatov, in 1909 - by I.A. German, in 1910 - by D.V. Shaposhnikov. Now they house the M.F.Vladimirsky Moscow Regional Research Clinical Institute (MONIKI).

Major metropolitan hospitals also emerged in the first half of the 19th century. In 1801, at the expense of funds bequeathed by Prince D.M. Golitsyn, the Golitsyn hospital building was erected in Moscow as per the design by M.F.Kazakov. It is assumed that the original author was V.I. Bazhenov. The group of buildings in the classical style stands back of the red line of Bolshaya Kaluzhskaya Street (modern Leninsky prospect). Facades and interiors of the hospital are in strict terse style, with the exception of the highly decorated church with semicircular light windows in the spherical dome (Figure 1). The architectural concept has some similarities with the Pavlovskaya hospital. At the hospital, a pharmacy, an ambulatory clinic, paramedic school, and maternity shelter were established.

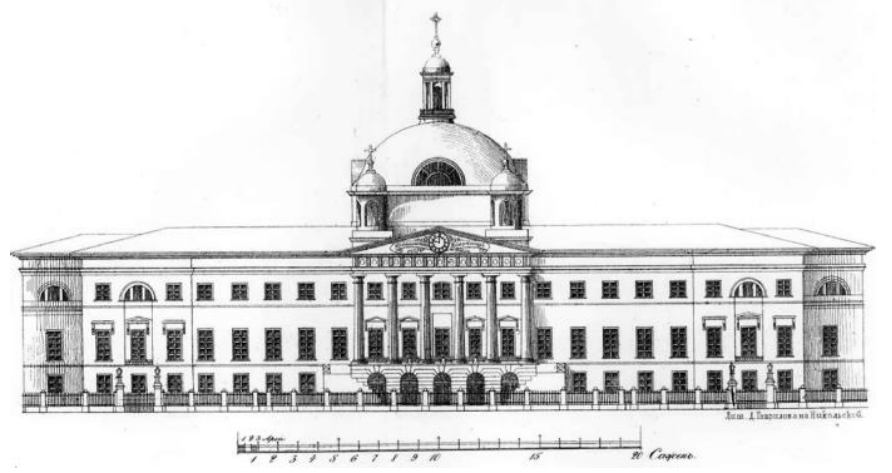

Fig. 1. The front facade of the main building of the Golitsyn hospital

Healthcare functions were performed by graph N.P. Sheremetyev Hospitium (1810). In the early 19th century, construction of the 1st City and Novo-Ekaterininskaya hospitals (opened after a fire in 1833) began. In 1806, the Mariinskaya hospital was opened on Liteyny Avenue, Saint Petersburg (G. Quarenghi), in 1819, an eye department was opened there. In 1834 in St. Petersburg, the Russia's first children's hospital - Nikolaevskaya (now the 5th Filatov Pediatric Clinical Hospital) was opened.

In 1805, in Russia, the first university clinic was opened on the basis of the Faculty of Medicine of the Imperial Moscow University (now, the I.M. Sechenov First Moscow State Medical University).

The construction of the group of buildings of the 1st Moscow City Hospital was funded from the city budget in 1828-1832 as per the design by O.I. Bove. The main building is located at the back of the yard, wings overlooked the red line of the Bolshaya Kaluzhskaya 
Street. The facade is marked by eight-column ionic portico and embossed pediment, the dome of the hospital church was decorated with paintings and stucco works (Fig. 2). It was subsequently merged with the Golitsyn, Lyubimovskaya and 2nd City Hospitals and was named after N.I.Pirogov. Now, it is the largest multidisciplinary hospital in Moscow [7].

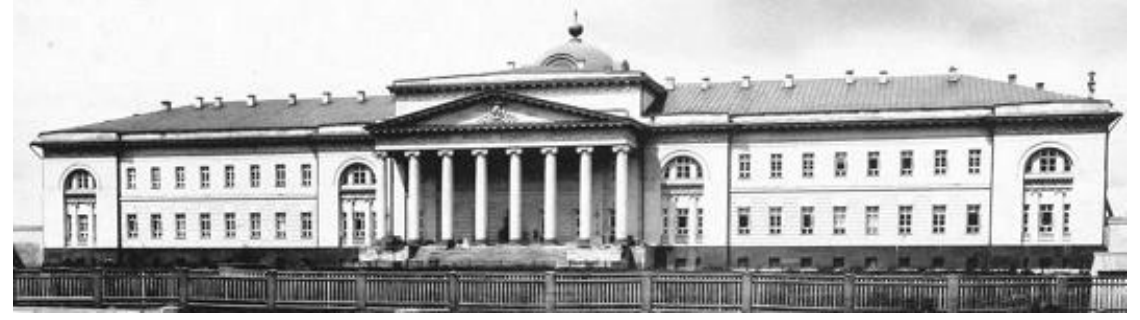

Fig. 2. The main building of the 1st Moscow City Hospital

From the mid-18th to mid-19th century, the health care was administered by the Public Assistance Department. The major health-care facilities were hospitals in several large cities, while almost no medical care was delivered to rural population.

During these years in Russia, the two main centers of medical science were formed: one on the basis of the Moscow University, the other on the basis of the St. Petersburg Medical-Surgical Academy. In St. Petersburg, the main directions were Surgery, Anatomy, Topographic Anatomy, and at the Moscow University - General Pathology, Therapeutics, Physiology. In 1803, in Russia, there were 1625 doctors; in 1812, they were 2776.

The feature of forming the hospital network in cities in that period is the understanding of the proper placement and establishment of unique healthcare zones. For example, in St. Petersburg, many healthcare centers were built in the Italian garden (modern Liteyny Prospekt). Here, the Mariinsky hospital for the poor (G. Quarenghi, 1805) was built, later an obstetric center, medical educational institutions, and other healthcare centers.

In 1842, the Permanent Hospital for Laborers was established, which occupied several buildings in Saint Petersburg (the Aleksandrovskaya Hospital). In 1864-1866, a special building at 132 Fontanka embankment was erected (by architect I.V. Strom), which is now occupied by psychoneurological dispensary.

In St. Petersburg, there was another Aleksandrovsky Hospital that represented wooden barracks for infectious hospitals. Now it is the S.P. Botkin Clinical Infectious Diseases Hospital, with 4-8-story brick buildings (3 Mirgorodskaya Street).

The St. Petersburg largest pediatric hospital was the Prince Peter of Oldenburg Children Hospital. The hospital buildings were erected along the perimeter of the quarter in 18671869, by architect Ts.A. Kavos (now, Raukhfus' Children City Hospital No. 19).

At the turn of 19-20th centuries in view of the need to create new forms of scientific activities, institutions of a new type emerged, i.e. medical research institutes. With a significant degree of conditionality, these institutions can be divided into three groups: clinical institutions, where along with the research in internal medicine, surgery, pediatrics, obstetrics and gynecology, etc., medical care is delivered; hygiene institutes conducting research in general and communal hygiene, occupational health, nutrition, children and adolescents; theoretical institutions studying problems of pathological physiology, morphology, virology, immunology, medical genetics, etc.

Typically, medical institutes had a narrow focus. Large clinical institutions can be exemplified by the N.N.Burdenko Neurosurgery Institute founded in 1932, and the N.N. Blokhin Russian Cancer Research Center operating since 1951.

Planning and construction of the most healthcare centers in Soviet time was far from being diversified, standard solutions based on prefabricated and modular structures were 
common. Buildings were mostly rectangular or $\mathrm{T}$-shaped in plan, thus ensuring the functionality, but being not sufficiently expressive.

In modern times, in Russia, establishment of multifunctional medical centers was developed, though not all of them occupy new buildings. The latter can be exemplified by the Medical Research and Educational Center at the Lomonosov Moscow State University, with a total area of 52.8 thousand sq.m, built in 2007-2013 (General Designer: SPC Giprozdrav JSC).

\section{Features of construction and reconstruction of medical buildings}

Healthcare facilities form the material basis of the healthcare system, which includes organizations, institutions, enterprises, scientific societies and individual specialists. In the Russian Federation, the healthcare is based on the functioning and development of the state, municipal and private health systems. Thus, the public healthcare includes public and administration healthcare authorities, medical and pharmaceutical organizations, supervisory, forensic expert and other organizations. A medical organization is a legal entity engaged in healthcare activities under an appropriate license [8]. Healthcare facilities provide inpatient and outpatient care.

If we split medical organizations into specialized and multipurpose, multipurpose shall include outpatient clinics and hospitals that deliver medical care for several, weakly interrelated healthcare types. Modern medicine envisages the increased attention to the patient. This concept aims at eliminating psychological discomfort during treatment and especially during the inpatient stay. In particular, research by psychologists show that an important factor giving confidence to a patient is the ability to move independently and find directions in a hospital. A separate ward gives great relief, which allows not to depend on the general condition of other patients, and to receive friends and relatives at a convenient time. Aesthetically balanced lighting and interior colors, imitation of home furnishing, placing photos and reproductions on the walls have positive impact on the wellbeing. The silence in the building, comfortable appliances and auxiliary facilities reduce the stress as well [9]. In Russia, some clinics cannot provide favorable psychological atmosphere for their patients yet, especially when the facility occupies an old run-down building, with low-performing utilities. In this regard, the issue of timely reconstruction of healthcare facilities becomes even more acute. It is very important to attract to the reconstruction project experienced professionals who know the specifics of healthcare facilities, understand the impact of internal environment on the psychological condition of patients. Reconstruction of multipurpose healthcare facilities may change almost all spaceplanning characteristics of buildings and structures. It is advisable to provide upgradability in the initial design, however, it is hard to predict the development of medicine, even for experienced architects. If you change the number of beds in the inpatient facility, first of all, the wards layout of the hospital is changed. When it is impossible to rearrange wards due to the design features of the building, the average number of beds in the ward is reduced as a rule. The total number of beds increases due to horizonal or vertical extension of the building. If technically feasible, WCs are arranged in wards, split-systems are installed, and utilities are reconstructed. The increase in the number of wards and beds may entail the reconstruction of evacuation routes, elevator and staircase sections, construction of porticos. Doctor's offices, diagnostic and treatment premises are located in the immediate vicinity of the wards in respective departments, usually on the same floor. The number and characteristics of these premises are determined by the department profile. It should be borne in mind that when commissioning a reconstructed facility, the compliance of solutions with currently applicable regulations, rather than the standards in force at the 
time of the original design, is checked. This may entail the need to change the layout and arrangement of offices. The most difficult is the reconstruction of surgical theaters, anesthetizing rooms, resuscitation wards, intensive care units, etc. Usually, surgical suites are placed in isolation from other premises, and are accessed through the gateways and sanitary inspection rooms. Surgery suites can be placed in a dead end of a floor corridor or in a separate unit. Re-planning of such premises must take into account strict zoning of premises and observance of sanitary conditions [10]. These very premises have the highest density of high-tech medical equipment, that implies utility engineering and transfer of large amounts of equipment. Outpatient department can be, unlike inpatient departments, built under walk-through pattern. When reconstructing, mobile reserve premises may be used, as most offices are relatively easy to move even to other floors. At the same time, it takes much rearrangement time to move some offices, such as x-ray, procedural, dental offices. Administrative and commercial premises of hospitals and outpatient clinics can be placed in separate buildings connected to the health-care part by passages and transport process communications.

\section{Opinion}

Thus, built at different times, healthcare facilities are mainly subject to then prevailing architectural styles: classicism, empire, eclecticism, constructivism, etc. At the same time, decoration of facades and interiors of inpatient and outpatient buildings must set the patient for positive perception of treatment methods and for expectance of high quality medical care. It is also important for the architecture of buildings to guide the health personnel to provide such care, patient and favorable attitude to the most serious patients.

In general, the analysis of the architectural features of hospital buildings shows that healthcare facilities become an important part of the cultural and historical heritage of cities and play a significant role in the architecture of the city. However, to improve the perception and increase the efficiency of such buildings, they must be maintained in good condition, repaired and reconstructed, recovering the lost appearance of monuments of history and culture.

\section{References}

1. G. J. Meulenbeld, D. Wujastyk, MBT, Studies of Indian Medical History, 234 (2001)

2. H. E. Müller-Dietz. Die Krankenhausruinen in Mihintale (Ceylon) (Jahrbuch der Deutschen Gesellschaft für Krankenhausgeschichte e.v., Historia Hospitalium Bd. 10, 65-71, 1975)

3. G. B. Risse, OUP, Mending bodies, saving souls: a history of hospitals, 56 (1990)

4. P. Horden, The Earliest Hospitals in Byzantium, Western Europe, and Islam (Journal of Interdisciplinary History, 35(3), 361-389, 2005)

5. R. E. McGrew, M. P. McGrew, McGraw-Hill, Encyclopedia of Medical History, 400 (1985)

6. URL:http://www.medievalists.net/2013/08/crusader-hospital-discovered-in-jerusalem/)

7. M.I. Vostryshev, S.Yu. Shokorev, Algorithm, Eksmo, All the cultural and historical monuments, $\mathbf{5 1 2}$ (2009)

8. Russian Federal Law No. 323-FZ On Fundamental Healthcare Principles in the Russian Federation (2011)

9. C. Jarrett, Is there a psychologist in the building? The Psychologist, 19(1), 592-594, (2006)

10. E.V. Orlova, International Research Journal, 3(5), 40-43, 2016) 